\title{
Integration of a Ground-Based Lightning Warning System into a Mining Operation in the Democratic Republic of the Congo ${ }^{\circ}$
}

\author{
Alistair D. Clulow, Sheldon Strydom, ${ }^{a}$ Bryan Grant, Michael J. Savage, ${ }^{b}$ \\ AND COLIN S. EVERSON \\ School of Agricultural, Earth and Environmental Sciences, University of KwaZulu-Natal, Pietermaritzburg, South Africa
}

(Manuscript received 12 January 2018, in final form 5 September 2018)

\begin{abstract}
Central Africa is a global lightning hot spot, with the tropical areas including the top 10 highest lightning-flashrate densities in the world. There are no lightning-locating-system networks available across most of Africa, however, and it becomes necessary to make use of real-time, ground-based lightning early warning systems. Such a system was established in the southern Congo basin at the Kinsevere copper mine and has been operational since early 2015 . The early warning system includes an electrical-field meter and a lightning-flash sensor, which produce two states of warning. Two years of data (July 2015-June 2016 and July 2016-July 2017) indicated a clear annual and daily peak in lightning activity, with an average lightning warning duration of $1.18 \mathrm{~h}$ and a maximum storm duration of $8.60 \mathrm{~h}$. The seasonal flash occurrence was reasonably constant over the two years but was variable at a monthly level during the lightning season. Analysis of alarm state showed that the majority of events start with an escalation to an alarm state of 2 but that, over two years, $69.3 \%$ escalated further to an alarm state of 3 . Alarmduration analysis indicated that more time was spent in alarm state 3 (warning) than alarm state 2 (caution). It was concluded that a single warning state would be suitable at this location and would simplify the warning system but that appropriate alarm-activation thresholds in electric field and flash distance need further assessment.
\end{abstract}

\section{Introduction}

Rain-producing thunderstorms are accompanied by lightning, which can be both beneficial and destructive. However, lightning is known to damage infrastructure, ignite severe wildfires (Nauslar 2014), and result in extreme human injury and fatality (Mulder et al. 2012). The progression of lightning research has resulted in studies focusing on ground-based detection and early warning systems, lightning formation and cloud electrification, (Avila and Pereyra 2000), and space-based lightning detection (Boccippio et al. 2002).

Despite atmospheric lightning being a familiar phenomenon, it remains, according to Dwyer and Uman

\footnotetext{
T) Supplemental information related to this paper is available at the Journals Online website: https://doi.org/10.1175/WCAS-D-180004.s1.

a ORCID: 0000-0002-5006-2029.

b ORCID: 0000-0001-6108-0874

Corresponding author: Sheldon Strydom, sheldon.strydom@ gmail.com
}

(2014), poorly understood. Stolzenburg et al. (1998) explain that, within a thunderstorm, several regions of positive and negative charges occur throughout the convective development. Lightning discharges produce transfer of charge to offset imbalances in these charged regions. In general, the charge structure of thunderstorms is dipole, with positively charged particles above negatively charged particles, or tripole, in which a dipole structure exists with the addition of lower-charged areas below (Stolzenburg et al. 1998). Charge transfers within a thunderstorm generally occur during the collisions between soft graupel (ice-encrusted snow pellets) and ice crystals at different temperatures (Dwyer and Uman 2014). A detailed review of thunderstorm electrification is provided by Stolzenburg et al. (1998) and Dwyer and Uman (2014).

Advances in instrumentation have recently enabled an improved understanding and detection of lightning (Dwyer and Uman 2014). This study investigates the operational implementation of a ground-based lightning detection and warning system at the Kinsevere copper mine in the southern Congo basin of the Democratic Republic of the Congo (DRC). 


\section{a. Lightning climatology}

In the early 2000s, numerous studies aimed to identify global hot spots of lightning activity (Albrecht et al. 2016). Investigations into the global variations of lightning, through the use of remote sensing technology, found a number of lightning-prone areas (Christian et al. 2003). One such study was completed by the National Aeronautics and Space Administration (NASA), which collected data between 1997 and 2014 using a lightning imaging sensor to produce a world lightning map indicating the annual lightning flashes per square kilometer. Furthermore, lightning-prone areas have been found frequently to be associated with regions of complex topography and with coastal regions under synoptic-scale convergence zones (Christian et al. 2003). Lightningprone areas, which experience strong seasonality, commonly experience more lightning during the convective rainfall season, and in eastern China Xia et al. (2015) found that both positive and negative lightning flashes occurred more frequently in the summer months. In the United States, flash-density maxima have been found to occur over the southeastern coast, as well as the Rocky Mountains and central Great Plains (Zajac and Rutledge 2001). As with eastern China, the United States experiences a majority of lightning during the summer months (Zajac and Rutledge 2001). However, these general perceptions of lightning cannot be applied across the globe. While previous studies indicate the importance of complex topography in enhancing convection processes and thus lightning, Xia et al. (2015) found a lower flash-density rate over the mountains of eastern China. In support of the general theory of lightning occurrence, Taszarek et al. (2015) found an increase in thunderstorm incidence in the mountainous regions of Poland but also noted the presence of a clear thunderstorm season during summer months and noted that positively charged cloud-to-ground lightning peaked in the winter months. It is clear that the occurrence of lightning is complex and is affected by numerous macro- and microfactors that are location specific.

The Congo basin (and thus the DRC) are the most notable of the African (and indeed global) lightning hot spots identified by Christian et al. (2003), Jackson et al. (2009), and Albrecht et al. (2016). Satellite remote sensing has indicated that the peak lightning activity in the DRC generally occurs between November and February, the summer months (Collier and Hughes 2011; Jackson et al. 2009). In the DRC, the flash-rate density exceeds 50 flashes per kilometer squared per year over large areas, especially in the central eastern parts (Fig. 1), while it ranges from 6 to 10 flashes per kilometer squared per year in the southeastern area (Albrecht et al. 2016).

\section{b. Lightning mortality}

Lightning has been estimated to result in roughly 6 deaths per million people per year in the developing world (Mulder et al. 2012), while in the developed world it can be as low as 0.42 deaths per million people per year (Blumenthal et al. 2012). Lightning-fatality and lightninginjury statistics for the DRC are not accessible, but using South Africa as a proxy may be useful. Both countries have areas with similar flash-rate densities and temporal characteristics of lightning (Roy and Balling 2014). The latest available lightning-fatality statistics for South Africa indicate a death rate of 1.5-8.8 deaths per million people each year. However, highly localized case studies have identified as many as 52 lightning-related deaths between 2001 and 2004 (Jandrell et al. 2009). In Malawi (also fairly close to the DRC), the annual lightning deaths are as high as 84 per million people (Mulder et al. 2012). Lightning-related injuries that do not result in death are more difficult to investigate, because comprehensive statistics are not maintained by any medical organization in Africa. It is also important to consider the influence of the population density of each country and how that factor may result in variation in lightning deaths. It is likely, however, that lightning injuries and fatalities in the DRC are at least comparable to, if not higher than, those of South Africa and Malawi.

\section{c. Lightning warning}

Lightning fatalities in the United States have been significantly reduced since the implementation and advancement of the National Lightning Detection Network, which utilizes ground-based remote sensing instruments to measure lightning radiation fields (Cummins and Murphy 2009). In addition, there are global networks [such as the World Wide Lightning Location Network (http://www.wwlln.net) and LightningMaps.org (http:// www.lightningmaps.org)] that provide near-real-time information on lightning strikes, but with low to no coverage of much of Africa. In developing countries such as the DRC, where economic activities such as mining have resulted in the relatively rapid growth of settlements in isolated areas with a high lightning occurrence, it is imperative that some form of lightning warning be considered for safety reasons.

This research describes the implementation of a ground-based lightning warning system at a mine in the DRC. The data collected provide information on the lightning-flash-rate characteristics from an area identified globally as having a high lightning-flash rate but with only satellite and other long-range measurement data of the area, which are insufficient for real-time operational warnings. From the results, we also consider 

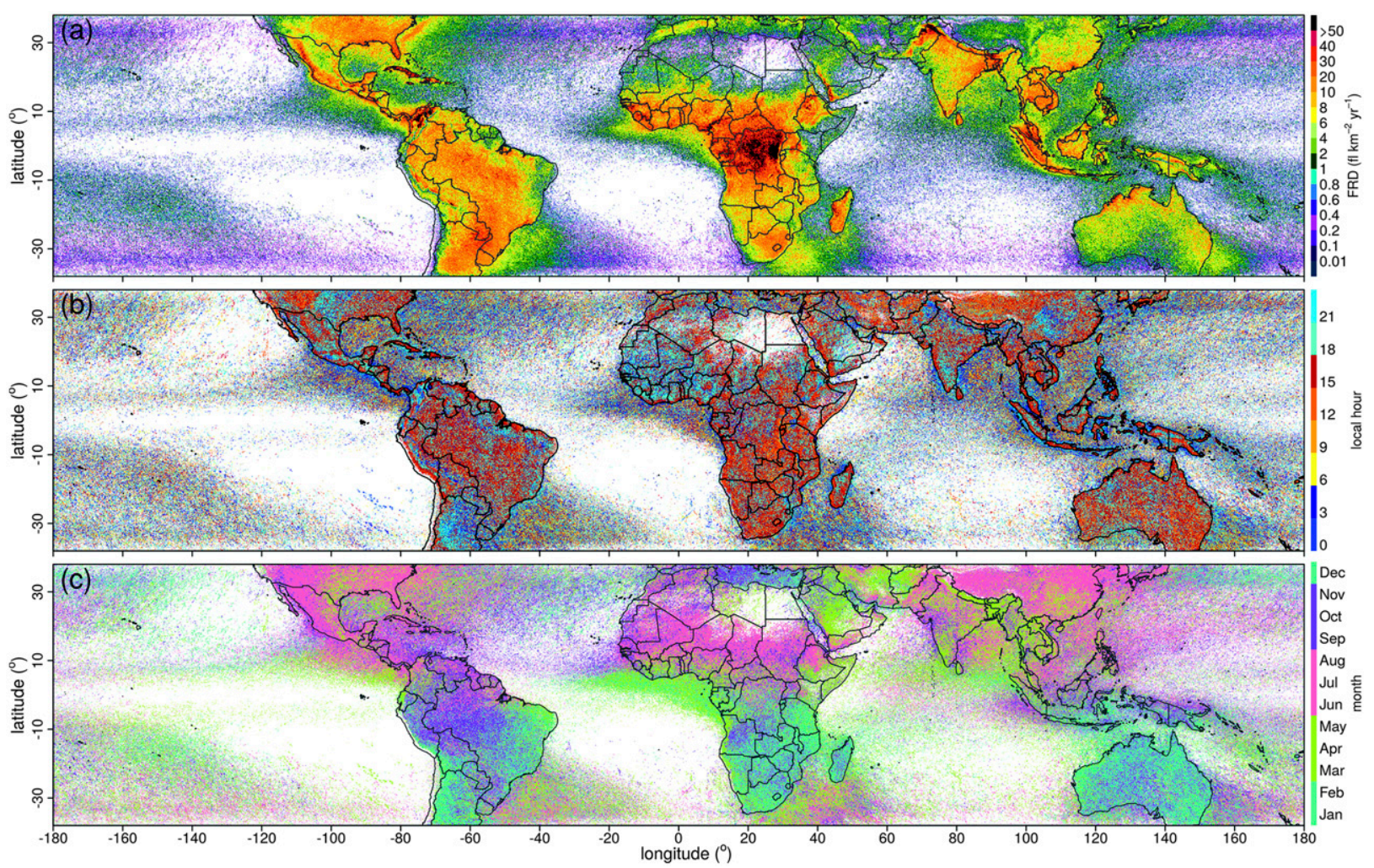

FIG. 1. (a) Global distribution and variability of total lightning (flashes per kilometer squared per year) between 1997 and 2014 , (b) diurnal variation of maximum flash-rate density, and (c) monthly variation of maximum flash-rate density (taken from Albrecht et al. 2016).

the translation of the measurements into an effective warning system that prioritizes safety and optimizes simplicity.

\section{Method}

\section{a. Site description}

The Congo basin covers roughly 1.2 million $\mathrm{km}^{2}$ and is generally underlain by a $200-300-k m$-thick lithosphere. A vast majority of the Congo basin is underlined by sedimentary soils and crusts dating back to the Mesozoic era (Kadima et al. 2011).

The Congo basin is considered to be one of the major convective regions in the global tropics (Zipser et al. 2006; Washington et al. 2013). A lack of ground-based meteorological stations in the region has resulted in the use of satellite-based remote sensing technologies to study the climate of the Congo basin. In terms of climate, the DRC experiences distinct wet and dry periods despite the equatorial location of the country (Jury and Mpeta 2009). A clear rainfall gradient is evident over the Congo basin extending from the drier southwest to the wetter northeast (Washington et al. 2013). In addition to the distinct bimodal rainfall season, the DRC is also prone to droughts on a 3-6-yr cycle (Jury and Mpeta 2009).

The study was conducted at the Kinsevere mine located in the southeastern Katanga Province of the DRC. The Kinsevere mine is located at $11^{\circ} 21^{\prime} 48^{\prime \prime} \mathrm{S}$ and $27^{\circ} 33^{\prime} 50^{\prime \prime} \mathrm{E}$ at an elevation of $1200 \mathrm{MSL}$ (Fig. 2). The southeastern region experiences a distinct rainfall season, with a mean annual precipitation of $1100 \mathrm{~mm}$. Air temperatures in the area range from roughly $26^{\circ} \mathrm{C}$ in summer to $5^{\circ} \mathrm{C}$ in winter (Booth et al. 2010). The total precipitation measured on site was $1334,1141,972$, and $992 \mathrm{~mm}$ in the summers of $2013 / 14,2014 / 15,2015 / 16$, 2016/17, respectively.

\section{b. Lightning warning equipment and communication system}

A lightning warning system (LWS) was installed at the Minerals and Metals Group, Ltd. (MMG), Kinsevere copper mine in January of 2015. The LWS was installed on a gravel area (known as a mill pad) with a radius of approximately $7 \mathrm{~m}$. The LWS uses two sensors to detect the threat of lightning. One-second measurements from an electric-field meter (model CS110 from Campbell Scientific, Inc.), positioned at a height of $2.54 \mathrm{~m}$ above 


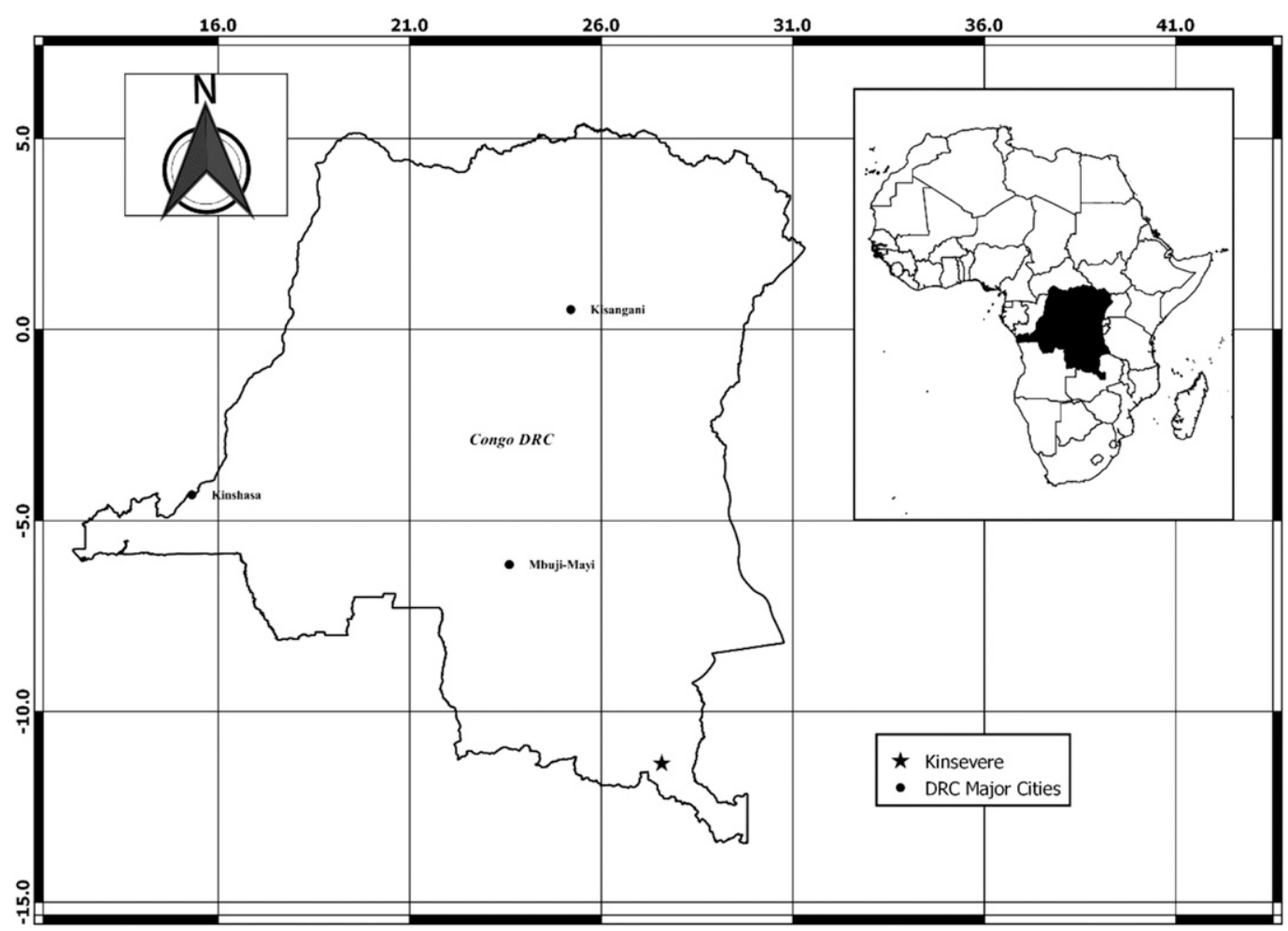

FIG. 2. Location of Kinsevere and other major cities in the DRC and Africa.

the ground surface, determined the electrical field (accuracy $\pm 5 \%)$ of the atmosphere $\left(\mathrm{Vm}^{-1}\right)$ and detected the presence of charged cloud in an area with a radius of approximately $11-16 \mathrm{~km}$ from the station. A lightning-flash sensor (model Strike Guard SG000 from Wxline, LLC) was installed at a height of $3.0 \mathrm{~m}$ above the ground surface. The SG000 detects optical and radio emissions of lightning flashes and, according to the manufacturer, classifies flashes into either of $0-16-\mathrm{km}$ and $0-32-\mathrm{km}$ ranges. The $0-32-\mathrm{km}$ category will mostly include flashes in the 16-32-km range but in rare cases may include flashes within $16 \mathrm{~km}$ because of the spatial capability of the measurement and therefore is stated to include $0-32 \mathrm{~km}$. These detected flashes include intracloud and intercloud flashes as well as cloud-to-ground strikes. The SG000 sensor does not differentiate between flashes and strikes, and henceforth the term flashes in this paper will include strikes. Serial data were transmitted from the SG000 to a datalogger (Campbell Scientific model CR1000M) via a fiber-optic link. The SG000 frequently performs a self test of sensor function, communication, and battery voltage to minimize malfunction during a lightning event. Measurements from both sensors were recorded every second, and averages or totals were calculated every 1,5 , and 60 (hourly) min by the datalogger. Photographs of the operational system can be found in the online supplemental material.
Data were transmitted every minute by $2.4-\mathrm{GHz}$ radio across a 900-m line of sight to the control room $(20 \mathrm{~m}$ above ground surface level), where they were stored on a server computer. The Campbell Scientific "Real Time Monitoring Center," version 4, software displayed the data and sent lightning status and system health (battery voltages, communication failures, and high internal relative humidity) e-mail messages to relevant mine personnel.

A single remote alarm system with lightning warning status beacons (Campbell Scientific model RA110) was located on the outside of the control room for good visibility to the surrounding offices and line of sight with the LWS. Data that indicated the lightning status were transmitted, over the radio connection, from the LWS on the ground every minute. The data were interfaced with the existing Vijeo Citect Supervisory Control and Data Acquisition (SCADA) monitoring system for the copper-processing plant that works in conjunction with a Quantum model Programmable Logic Controller (PLC; Schneider Electric Industries, SAS) using process field bus ("Profibus") protocol to drive a 380-VAC (alternating-current voltage) siren. Eight additional RA110 stations were installed across the mine site (area of $6 \mathrm{~km}^{2}$ ) with local area network (LAN) connectivity to the server computer. At an electrowinning site, fiber-optic 
TABLE 1. Conditional logic describing the increase in warning states from 1 to 3 according to data from the electric-field meter and flash sensor. Either/or logic applies in terms of the electric-field-meter data and flash-sensor data.

\begin{tabular}{lccc}
\hline \hline State & Beacon color & Electric-field meter & Flash sensor \\
\hline 1 = all clear & Blue & $\begin{array}{c}\text { 1- and 10-min running averages of the } \\
\text { electrical field }<1000 \mathrm{~V} \mathrm{~m}^{-1} \\
\text { 1-min running average of the electrical } \\
\text { field }>1000 \mathrm{~V} \mathrm{~m}^{-1}\end{array}$ & $\begin{array}{c}\text { No flash detected within a 32-km radius } \\
\text { for 30 min } \\
\text { Flash detected within a 32-km radius } \\
\text { 1-min running average of the electrical } \\
\text { field }>2000 \mathrm{~V} \mathrm{~m}^{-1}\end{array}$ \\
\hline
\end{tabular}

cable, rather than the shielded category 6 (Cat 6) that is used at the other sites, was installed to avoid interference. The networked RA110 stations requested data at 1-min intervals from the server computer, and strobe lights indicated the lightning warning status. At the two sites farthest from the 380-VAC siren, smaller sirens (LGM Products, Ltd., model Nexus 110) were included with the beacons in the RA110 warning system because the main siren could not be heard clearly at these locations.

Power was a critical consideration at each site because of the frequency and duration of power failures at the site and the importance of uninterrupted operation of the lightning warning system. Initially, a $9 \mathrm{~A}$ h battery with 1-A charger was used for the CS110 and RA110. Later, an additional battery was added in parallel, resulting in a total storage capacity of $18 \mathrm{~A} \mathrm{~h}$. At the eight additional RA110 stations added, a 24 A h battery was used with a capability of operating for approximately $24 \mathrm{~h}$ on the battery supply.

The measurements of the atmospheric electric field and lightning flashes were translated into three possible states or conditions. "All clear" (state 1) indicated no lightning warning and was represented by a blue strobe beacon. "Caution" (state 2) indicated an imminent threat and was represented by a yellow strobe beacon. "Alarm" (state 3) indicated dangerous conditions and was represented by a red strobe beacon. No universal warning criteria for electric fields exist, and 1000 (caution) and 2000 (alarm) $\mathrm{V} \mathrm{m}^{-1}$ were used according to the Naval Seas Systems Command (NAVSEA) and NASA Launch Pad Lightning Warning System as thresholds to govern the activation of the three states (A. Hinckley, Campbell Scientific, Inc., 2017, personal communication).
Either/or logic was applied to the outputs from the electric-field-meter and SG000 flash-sensor measurements to ascend into higher alert states (Table 1) and descend to lower alert states (Table 2). Once in an alert state, the system only descends into an "all clear" state when there have been no flashes for $30 \mathrm{~min}$ and/or the electric field has dropped below a dead-band exit threshold. For the electric-field outputs, there is a dead band between ascending into a state of alert and descending out of the state of alert to prevent rapid activation and deactivation if the electric-field levels were to fluctuate around the entry threshold. The system goes to a state $=0$ (all beacons are deactivated and e-mail messages are sent to alert operators) if there is a potential problem such as low battery voltages, high internal relative humidity, or sensor failure.

A detailed MMG common lightning procedure documents the procedures to be followed to monitor, detect, communicate, and respond to lightning events. Responses to the various levels of lightning warning (alarm state 2 or 3 ) depend on the current operations. In outdoor operations, for example, all work ceases for an alarm state of 2 or 3 and people move to safe shelters or use Earth potential rise-mitigation mats. Some vehicular operations can continue under an alarm state of 2, but operation under an alarm state of 3 depends on the vehicle canopy structure, the presence of lightning masts, and whether the tires have been inflated with nitrogen. Operations can resume when the warning siren is silenced and when the warning strobe returns to a warning state of 1 (see Table 1).

Summaries of 1-min data output were analyzed over a 2-yr period to assess lightning occurrence and

TABLE 2. Conditional logic describing the decrease in warning states from 3 to 1 according to data from the electric-field meter and flash sensor. Either/or logic applies in terms of the electric-field-meter data and flash-sensor data.

\begin{tabular}{|c|c|c|c|}
\hline State & Beacon color & Electric-field meter & Flash sensor \\
\hline $2=$ caution & Yellow & $\begin{array}{l}\text { 1- and 10-min running averages of the } \\
\text { electrical field }<1000 \mathrm{~V} \mathrm{~m}^{-1}\end{array}$ & $\begin{array}{l}\text { No flash detected within a } 16-\mathrm{km} \text { radius } \\
\text { for } 30 \mathrm{~min}\end{array}$ \\
\hline $1=$ all clear & Blue & $\begin{array}{l}\text { 1- and 10-min running averages of the } \\
\text { electrical field }<500 \mathrm{~V} \mathrm{~m}^{-1}\end{array}$ & $\begin{array}{l}\text { No flash detected within a } 32-\mathrm{km} \text { radius } \\
\text { for } 30 \mathrm{~min}\end{array}$ \\
\hline
\end{tabular}




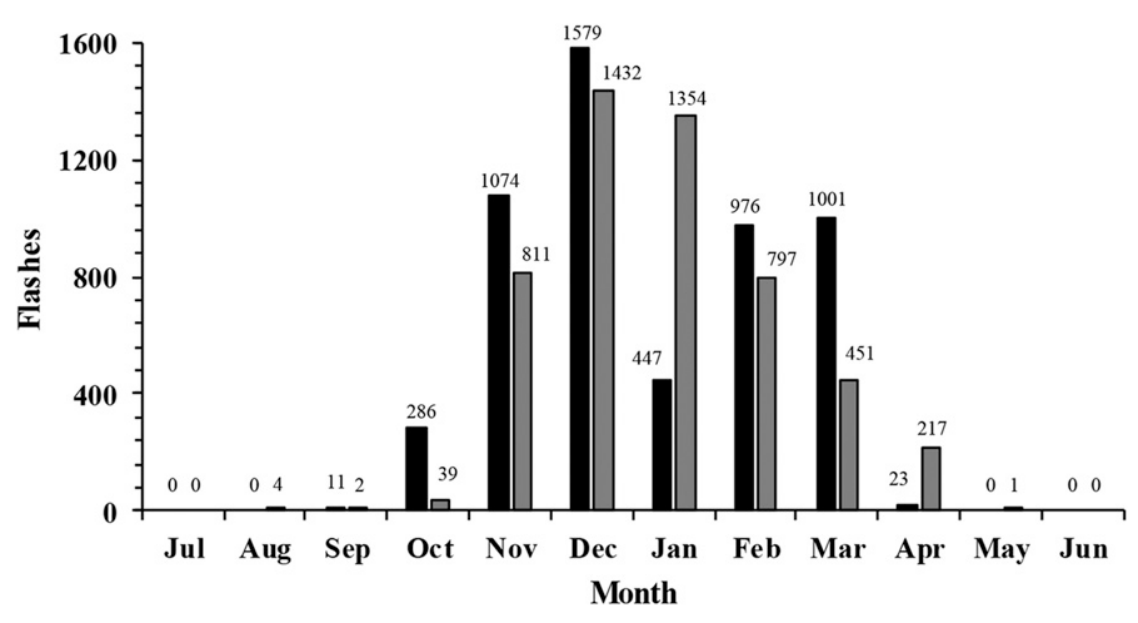

ロ 2015/16 $\square 2016 / 17$

FIG. 3. Monthly distributions of total lightning flashes for 2015/16 and 2016/17 within the 32-km range.

electric-field levels. Because of the highly seasonal nature of rainfall, thunderstorms, and therefore lightning in the DRC, the data were split into two periods from July 2015 to June 2016 and from July 2016 to June 2017 during assessment to avoid splitting the summer rainfall period. Time series analysis was utilized to investigate the temporal nature of lightning at the site, and simple univariate, descriptive statistics were used to determine the operational characteristics of the LWS. In reporting on annual flash densities, the $0-16-\mathrm{km}$-radius measurements were used, because this area is where the sensor has greatest detection efficiency. A 5\% adjustment was made in converting the detection volume of the SG000 (a semicircle) to the detection volume of a cylinder of atmosphere (as seen by a satellite) but only up to a height at which lightning typically occurs $(6-9 \mathrm{~km})$.

A distinction was made between alarm activation and alarm escalation. Activation describes the fulfillment (and possibly the repeated fulfillment measured every minute during an alarm) of an alarm state 2 or 3 , whereas escalation describes the fulfillment of alarm 2 or 3 but with an increase to a higher alarm state always. An event is defined as an escalation above an alarm state of 1 , and it is separated from other events by another alarm state 1 .

\section{Results}

\section{a. Temporal distribution of lightning flashes and electric field}

Throughout the 2015/16 and 2016/17 summer periods (Fig. 3), lightning flashes occurred mainly in the months from September to April, with December (1579 flashes in 2015/16) being the most active month on record. Total annual flash count for the $0-16-\mathrm{km}$ range was 2678 and 2511 in 2015/2016 and 2016/17, respectively (6.7\% difference). In the $0-32-\mathrm{km}$ range (this includes flashes in the $0-16-\mathrm{km}$ range), there were 5397 and 5108 flashes in 2015/16 and 2016/17, respectively (5.7\% difference). The annual average flash density was 3.4 flashes per kilometer squared per year after a $5 \%$ correction for the difference in volume between a semicircle (as detected by the SG000) and a cylinder (as detected by satellite) up to a height of $5 \mathrm{~km}$ above Earth's surface. The winter months (May, June, July, and August) experienced little to no activity (Fig. 3), with no flashes in 2015/16 during this period and only five flashes in total during 2016/17 over the 4-month period. Investigation of data from a collocated meteorological station (not included) indicates clear-sky conditions when these flashes occurred, and they are likely due to focused solar irradiance on the SG000 from a reflective surface and not lightning flashes. This is supported by the warning state of 2 (caution) of the lightning flashes (Figs. 4a,b), which indicates a weak flash intensity. Despite reasonable agreement in annual flash totals, there is some variability in monthly flash totals (Fig. 3). The 2015/16 lightning season started earlier in the year (286 flashes in September 2015) than the 2016/17 season (39 flashes in September 2016). The 2015/16 year also ended sooner than the 2016/17 lightning season. The flash count in January, in particular, was different by 907 flashes, although it was noted that there were 7 days of data missing during January 2016, which would narrow this discrepancy. Note that differences in 
a.

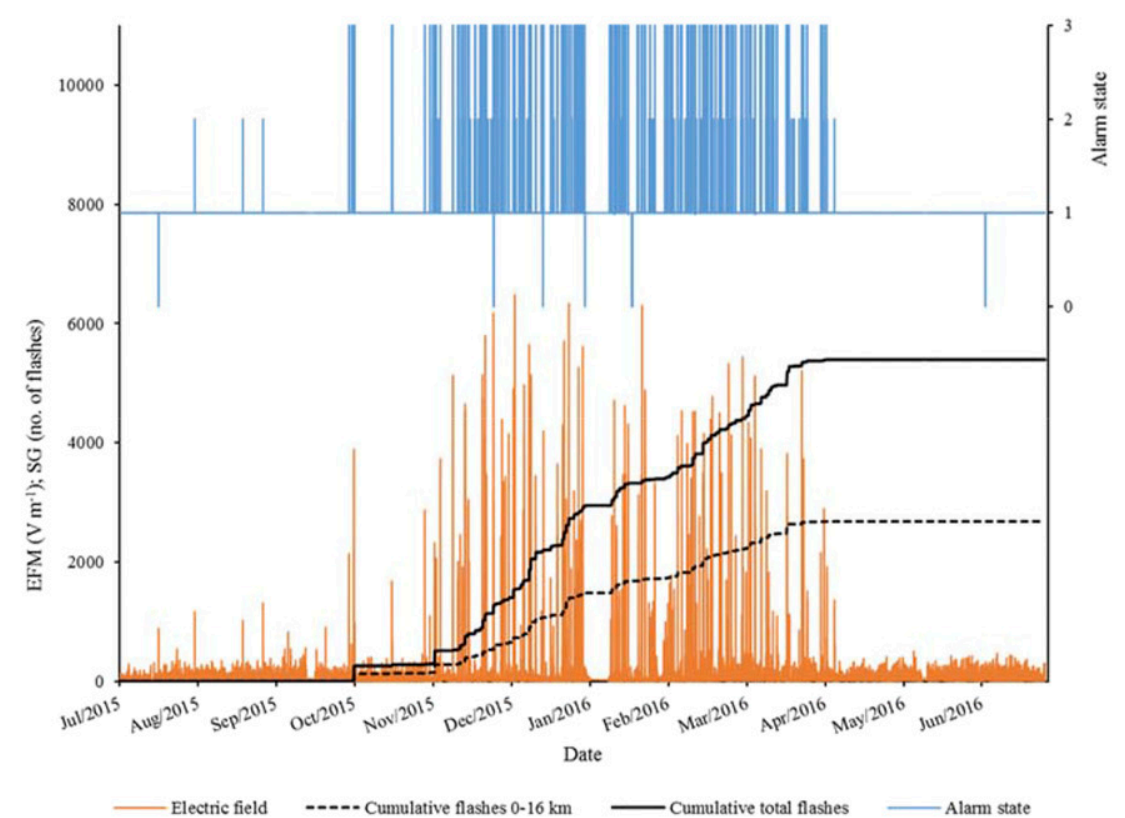

b.

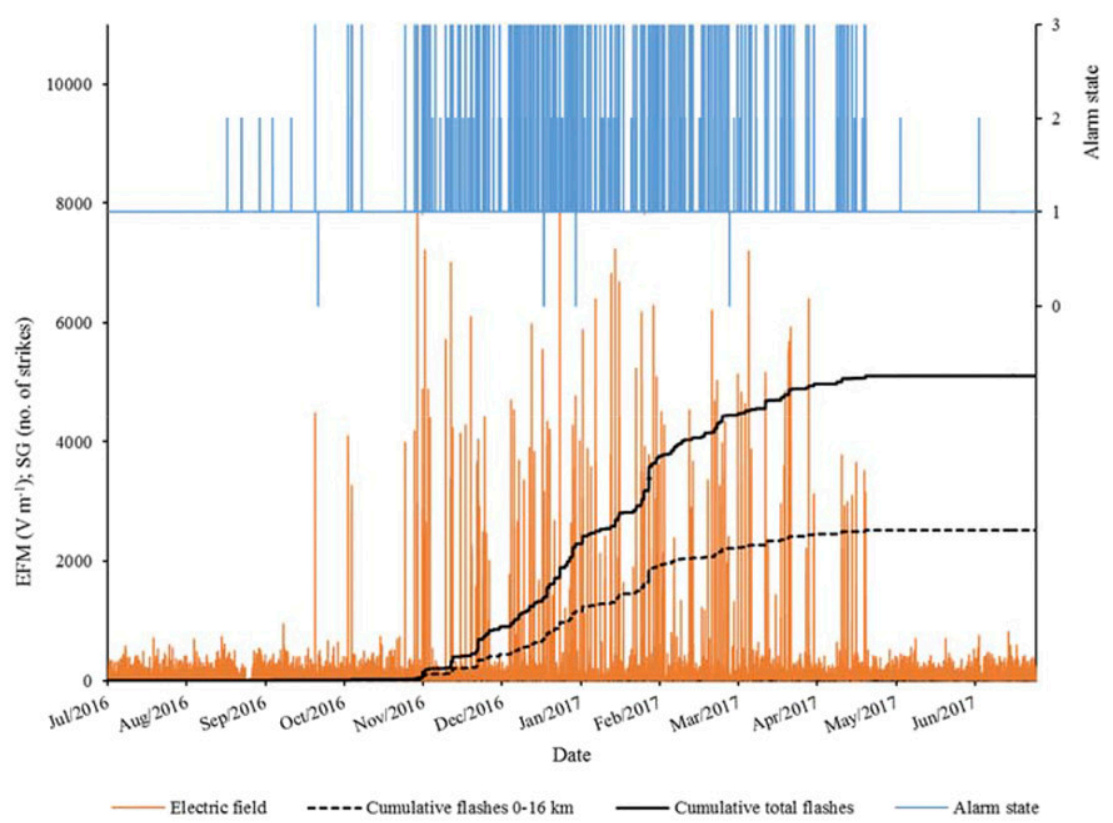

FIG. 4. Annual variations in the electrical field (1-s data averaged every $1 \mathrm{~min}$ ) and cumulative flashes in the $0-16-\mathrm{km}$ category and the $0-32-\mathrm{km}$ category (includes $0-16-\mathrm{km}$ category) for (a) 2015/16 and (b) 2016/17.

data-collection periods and measuring equipment used may result in different lightning-flash densities when comparing results presented here with other studies.
The absolute electric field generally fluctuated between 0 and $1000 \mathrm{~V} \mathrm{~m}^{-1}$ during winter, with the exception of the early part of the 2015/16 off-season during which on three occasions the electric field measured 


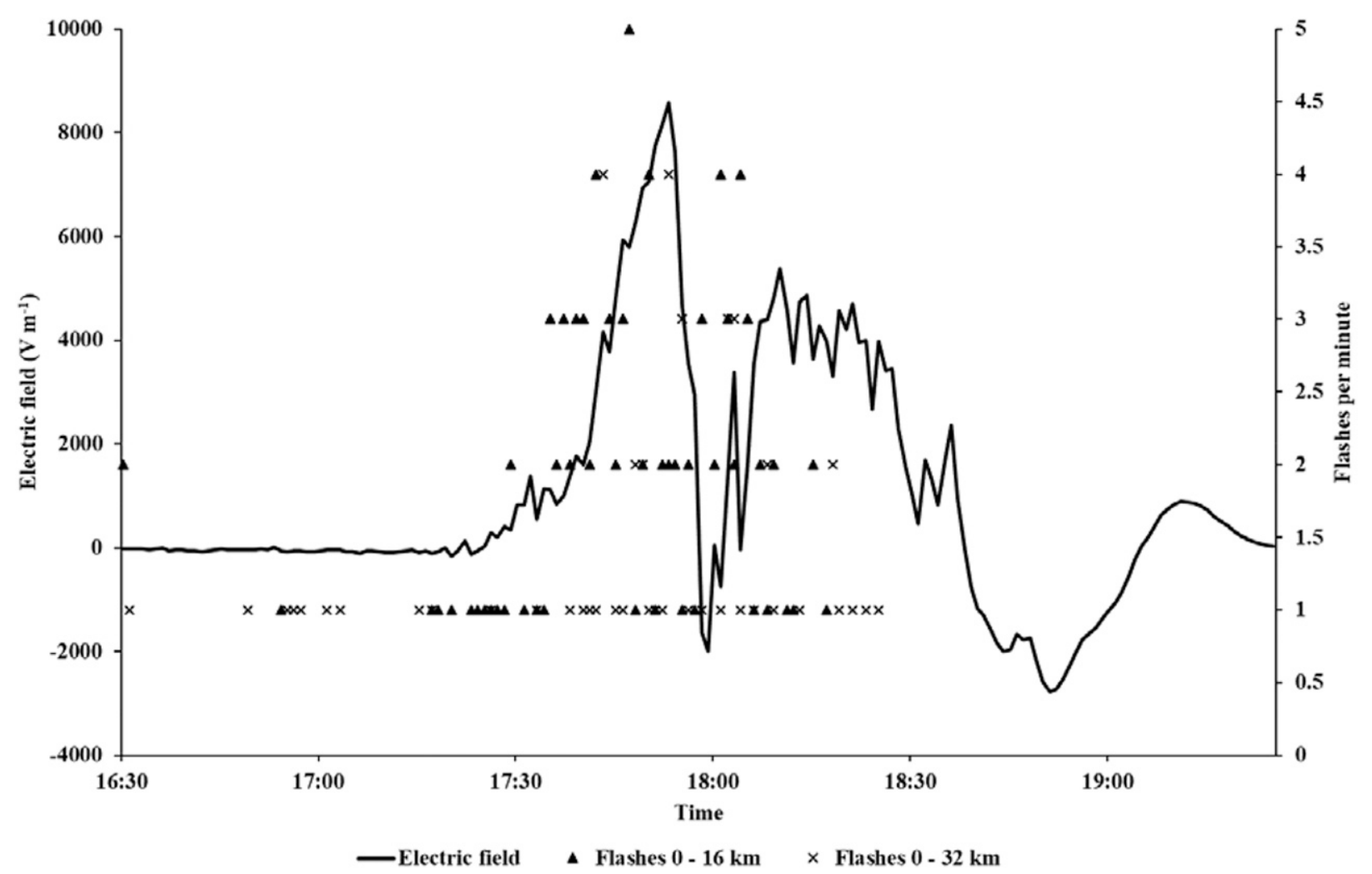

FIG. 5. Temporal progression of a storm event with 1-min totals of lightning flashes and 1-min averages of electric field (all from 1-s data).

slightly over the $1000 \mathrm{~V} \mathrm{~m}^{-1}$ threshold to trigger a state $=2$ briefly (Figs. 4a,b). During the lightning season of 2015/16 the electric field fluctuated as high as $6500 \mathrm{~V} \mathrm{~m}^{-1}$, and in $2016 / 17$ it fluctuated up to $7700 \mathrm{~V} \mathrm{~m}^{-1}$, but it was mainly below $6000 \mathrm{~V} \mathrm{~m}^{-1}$ during both seasons.

Missing data can be identified as periods in which the electric field is zero (Figs. 4a,b). In the 2015/16 data, there is a period of 7 days in January for which data are missing during the peak lightning season (as a result of corruption of the datalogger operating system) and then two more periods out of season in September 2015 (8 days-computer power failure) and May 2016 ( 2 days-computer power failure). In the 2016/17 data, there were only 3 days of data missing because of computer downtime. During these computer-power-failure events, the lightning warning system was still functional as the main RA110 at the control room, operating the 380-VAC siren, continued to communicate directly with the LW110 system on the ground. An alarm state of zero indicates a problem with the system. This occurred briefly (a few minutes) on six occasions in 2015/16 and four occasions in 2016/17 and was due to either low battery voltages during power failures or a relative humidity of $>60 \%$ inside the electric-field meter (a failed gasket).
Individual storms varied over the summer seasons in intensity and duration. Figure 5 describes the progression of a 3-h-long storm event that occurred on 25 December 2016 in which two lightning flashes within $16 \mathrm{~km}$ of the site first caused the alarm state to be $>1$. Over the following hour, there were a number of flashes within 16 and $32 \mathrm{~km}$ of the site. After an hour in alarm conditions, the atmospheric electric field started to increase, reaching $8500 \mathrm{~V} \mathrm{~m}^{-1}$. During this time, there were numerous flashes, with a maximum of five flashes in a 1-min period within $16 \mathrm{~km}$ of the site. The atmospheric electric field fluctuated rapidly after $1.5 \mathrm{~h}$ from 8500 to $-3000 \mathrm{~V} \mathrm{~m}^{-1}$ and then back to $5800 \mathrm{~V} \mathrm{~m}^{-1}$. Flashes ceased after about $2 \mathrm{~h}$, but the atmospheric electric field only stabilized later, keeping the system in an alarm state of $>1$ for up to $3 \mathrm{~h}$.

Alarm-state escalations occurred throughout the night and day in both 2015/16 and 2016/17; however, the general distribution (Fig. 6) indicated that there were times in the day at which escalations were more likely and other times at which escalations were less likely. There was a general increase in alarm-state escalations from roughly midday in both lightning seasons, with the peak lightning period in both seasons being from 1600 to 1700 local time. The number of escalations decreased at roughly 1900 local time, with a low level of escalation 
a.

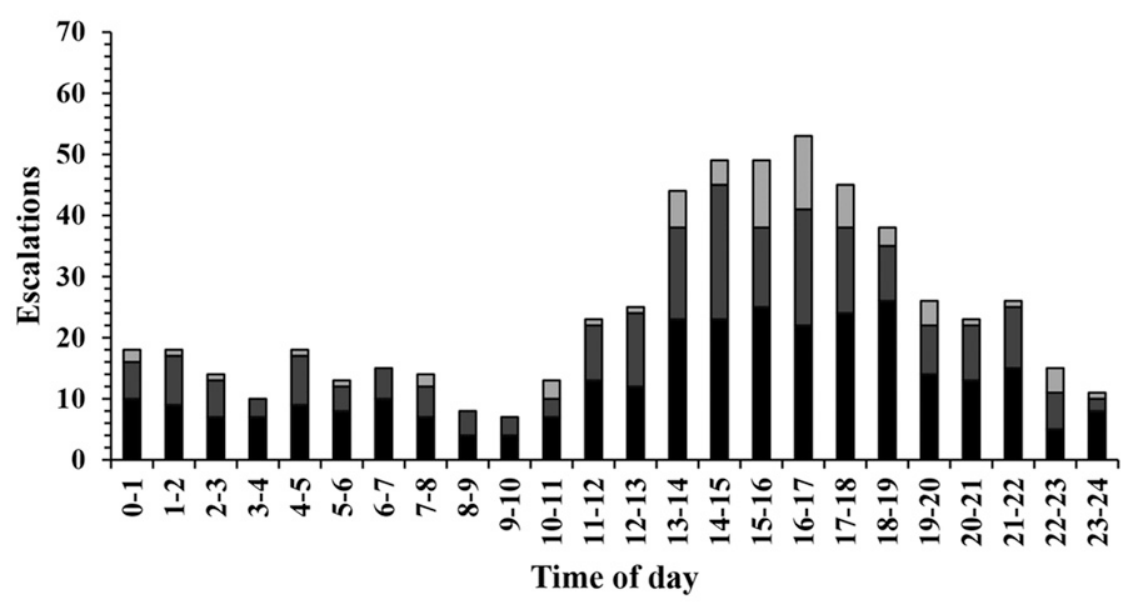

$\square 1$ to $2 \square 2$ to $3 \square 1$ to 3

b.

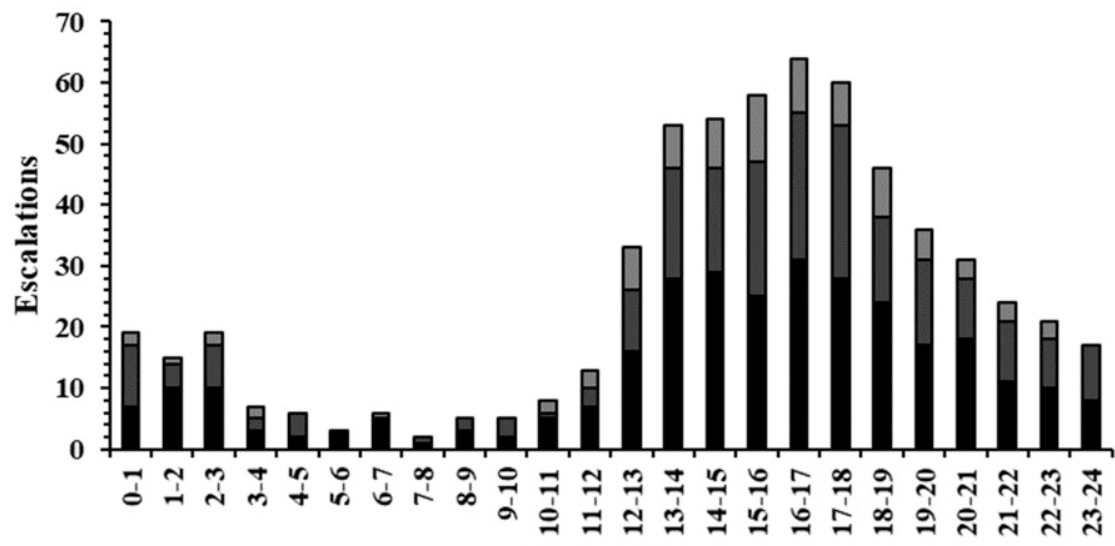

Time of day

$\square 1$ to $2 \square 2$ to $3 \square 1$ to3

FIG. 6. Diurnal variation in escalation states for (a) 2015/16 and (b) $2016 / 17$.

lasting throughout the night and morning period. The most noticeable difference between 2015/16 and 2016/17 was that, despite a small difference in total flashes that was reported previously $(5.7 \%)$ and a similar total number of escalations between the two seasons (575 and 605, respectively), there was a difference in the distribution of the escalations during the day. There was a lower number of escalations in the early-morning hours (0300-0900) during 2016/17 and a greater number of escalations during the peak lightning period (1200-1900) in 2016/17.

\section{b. Warning duration}

In 2015/16 the average length of warning event was $1.17 \mathrm{~h}$, with maximum duration of $7.45 \mathrm{~h}$ and minimum duration of $0.02 \mathrm{~h}$. In 2016/17 the average warning event was $1.19 \mathrm{~h}$, with maximum duration of $8.60 \mathrm{~h}$ and minimum duration of $0.02 \mathrm{~h}$. The majority of time in 2015/16 (7999 h-94.8\%) and 2016/17 (8278 h-94.7\%) was spent in alarm state 1 (all clear; Fig. 1 in the online supplemental material). Time spent in alarm state 2 was also similar in 2015/16 (169h) and 2016/17 (163 h). Again, time spent in alarm state 3 was similar in 2015/16 (266 h) and 2016/17 (297 h). However, in 2015/16 the total time spent in alarm states 2 and 3 was $2 \%$ and $3.2 \%$, respectively, whereas in $2016 / 171.9 \%$ and $3.4 \%$ were spent in states 2 and 3, respectively. It was therefore noted that more time was spent in alarm state 3 than in alarm state 2 for both measurement periods. 


\section{c. Events and alarm-state escalation}

From a total of 575 escalations, there were 372 events in 2015/16, because some of the escalations were from a 2 to a 3 and therefore were already a warning event (Fig. 2a in the online supplemental material). In 2016/17 there were slightly more escalations (605) and 387 warning events in total. In 2015/16, 305 (82\%) of the events commence as an escalation from a 1 to a 2 , but $203(66.6 \%)$ escalated further to a warning state of 3 . A similar pattern was observed in 2016/17, with $72.0 \%$ (69.3\% average over 2 years) of the state- 2 alarms escalating to state-3 alarms.

The termination of events (Fig. 2b in the online supplemental material) describes the highest state of escalation reached during an event. In 2015/16, only $102(27.4 \%)$ of the events ended in an alarm state of 2 whereas $170(72.6 \%)$ of all events ended in an alarm state of 3. Similar results were found in 2016/17, for which slightly more $(78.0 \%)$ ended in alarm state 3 and fewer $(22.0 \%)$ resulted in alarm state 2 . This result shows that, of the events that escalated to an alarm state of 2 , the majority during both years escalated further to a state of 3 . Events finally terminate fully by de-escalating back to 1 (see Table 2).

\section{d. Alarm trigger}

From the dual-sensor system (SG000 and CS110), the trigger-causing escalations from alarm state 1 to alarm states 2 and 3 were assessed and were found to have occurred primarily as a result of flashes in both 2015/16 and 2016/17 (Figs. 3a and 3b in the online supplemental material). Flashes were responsible for $66.8 \%$ of the escalations to alarm state 2 and $74.6 \%$ of the escalations to alarm state 3. Similar results were found for 2016/17, with flashes causing $69.1 \%$ of the escalations to alarm state 2 and $66.9 \%$ of the escalations to alarm state 3 . Very rarely did both sensors cause an escalation simultaneously (this occurred only twice in 2016/17).

Over 2.5 years of operating time, the only permanent damage to the equipment was to an RA110 network adaptor and a gasket seal on the CS110. The nearby network switch was damaged by a lightning strike that damaged the network adaptor. The RA110 was well grounded, and no other components were damaged. The gasket seal leaked because the thread holding the CS110 cover in place was stripped.

\section{Discussion}

All early warning systems require four elements to be efficient and effective. First, some knowledge of the potential risk is required (Basher 2006), such as identifying a potential hazard, and understanding the human or societal vulnerabilities. Second, an effective warning system requires monitoring capabilities. Third, the system requires some communication or warning dissemination capability. Fourth, the system requires a response capability (Basher 2006). The LWS at Kinsevere has successfully met all four requirements in an area without alternative wide-area or long-range detection systems such as are available in Europe and the United States. The implementation of the LWS measuring electrical field and lightning flashes indicates that the management team at Kinsevere is well aware of the potential lightning hazards.

The ground-based measurements at Kinsevere have provided a useful comparison with satellite annual flash-density data. The annual flash density of 3.4 flashes per kilometer squared per year provided by the groundbased measurements is less than those detected in the vicinity of Kinsevere by satellite (6-10 flashes per kilometer squared per year; Fig. 1), although there is a noticeably lower lightning-flash density in the southeastern area of the DRC in comparison with the rest of the DRC and it is possible that the Kinsevere measurements capture data more precisely than do the courser-scaled satellite imagery. In addition, numerous studies (Cummins and Murphy 2009; Thompson et al. 2014; Nag et al. 2015) report significant complexity with regard to comparison of these two techniques. The complexities arise from the differences in spatial scales represented and the sensors used for ground-based and regional measurements when compared with sensors used from satellites. The emissions detected by groundbased flash sensors typically measure radio frequencies (although the SG000 measures radio and optical emissions), whereas satellite-based lightning sensors detect optical emissions. Further complications include the presence of high cloud, which hinders satellite detection, as well as tracking the specific location of the satellite on Earth's surface; the viewing time for a location on Earth is typically on the order of only $90 \mathrm{~s}$ (Nag et al. 2015), as is the case with TRMM (Fig. 1). Despite these challenges, NASA was able to derive a useful global map of lightning occurrence despite it not necessarily agreeing well with ground-based results. However, Nag et al. (2015, p. 83) further explain that, "groups of events having high radiance in satellite-based LLS [lightninglocating systems] data sets are not necessarily correlated with lightning events having high peak currents in ground-based LLS data sets." Thompson et al. (2014) found that groups of events detected as high radiance by satellite sensors had a coincidence with ground-based sensors about one-half of the time. The data do compare better to the Global Lightning Dataset 360T 
(GLD360T) provided by Vaisala, Inc. (Hembury and Holle 2011), which also shows the Kinsevere area as having the lowest flash density within the DRC of approximately 4 flashes per kilometer squared per year. This dataset therefore provides the first local groundbased insights toward describing the characteristics of lightning in the DRC.

The annual variations in lightning-flash rate indicated a clear seasonality (summer/wet months). Annual variations in lightning between 2015/16 and 2016/17 supported the notion of the area experiencing a distinct rainfall season as highlighted by Booth et al. (2010). As with countries or regions discussed earlier, a large majority of lightning incidence occurred in the summer months. However, warnings were not only limited to summer months, and there were 6 unseasonal escalations in 2015/16 and 10 in 2016/17 that were (in terms of flashes) likely to be false alarms, where false alarms are alarm activations by sources that are not associated with lightning such as high-voltage electrical shorts in nearby power supplies or flashes of light from windows. In terms of electric-field false alarms, these can occur as a result of natural fluctuations in the electric field of the atmosphere or as a result of dust and charged particles accumulating on parts of the electric-field meter, causing elevated results from the electric-field meter. Therefore, regular cleaning of the electricfield meter is required.

Three escalations in 2015/16 and three in 2016/17 resulted from an electric-field measurement that just reached the $1000 \mathrm{~V} \mathrm{~m}^{-1}$ threshold, triggering an alert state of 2. In all of these cases, there was no indication of storm weather (cloud-affected solar irradiance, high wind speeds, high relative humidity, or sudden decreases in air temperature or pressure), and they are likely false alarms. Variations in the electrical field that trigger alarm escalations are likely not a result of dust and charged particle accumulation on the equipment (known to cause errors in electrical-field measurement) because the measurements returned to normal very quickly; they can more likely be attributed to several nonthunderstorm meteorological processes. Increases in the electrical field have been observed as a result of changes in local aerosol concentrations that stem from changes in wind speed and direction (Bennett and Harrison 2007). Advection of charged aerosols across the site will likely result in a fluctuation of the electrical field. Precipitation (convective or stratiform in nature) is also often charged and can result in changes in the electrical field. Increases in the electrical field preceding lightning strikes are likely due to changes in the microclimate ahead of thunderstorms. Cold-pool regions of thunderstorms may also result in changes in wind speed and direction, further advecting aerosols and other charged particles ahead of a thunderstorm. Changes in air temperature and relative humidity have also been shown to result in fluctuations in the electrical field (Bennett and Harrison 2007). Suspected false escalations as a result of flashes produced a minimum alarm time of $30 \mathrm{~min}$, but the electric-field escalations were just a few minutes in duration (see Tables 1 and 2 for details). These few false alarms during the winter period, when there is clearly no storm activity, could have a negative impact on the usefulness of the lightning warning system through a reduced confidence among the employees with regard to the accuracy of the warning system. These false escalations may indicate a need to adjust the minimum electric-field threshold for a state-2 warning to be slightly higher than $1000 \mathrm{~V} \mathrm{~m}^{-1}$ (as was initially implemented) so that natural fluctuations measured in winter do not trigger the warning system. In addition, during the winter months, which were determined to be May-August, only flashes within $16 \mathrm{~km}$ could be used to trigger an escalation to minimize weaker signals that were possibly related to light or frequency noise.

It was noted that the annual lightning count was reasonably consistent but that the monthly lightning count was variable. Christian et al. (2003) found that interannual variability is much smaller than diurnal or seasonal variation. This result would suggest that seasonal lightning count could potentially be predicted but not monthly lightning totals. The 2015/16 lightning season commenced slightly earlier than 2016/17 and ended slightly earlier, with September and October generally being the start of the lightning season and April the end of the lightning season. It seems highly unlikely that lightning would occur during May, June, July, or August, and the events recorded during this time were most likely false alarms as discussed above. Analysis of the monthly variation of lightning activity at Kinsevere yielded results similar to those of Albrecht et al. (2016).

Trends in the diurnal variation of lightning-flash rates between 2015/16 and 2016/17 emphasize the role of convection in lightning incidence. Lightning incidences (and increases in the electrical field) peaked between 1600 and 1700 local time, indicating the requirement for surface warming to aid in convection processes. This again agreed with results from Albrecht et al. (2016) and the conclusions of Christian et al. (2003) who found that strong convection leading to lightning is driven more by local solar flux (hence the large late-afternoon maximum) than by changes in large-scale circulation patterns. The diurnal pattern of escalations (Fig. 6) also showed that in 2016/17 there were noticeably fewer 
escalations in the early morning and more escalations during the peak lightning period of the afternoon. This difference in the diurnal trends possibly indicates a subtle difference in the nature and development of the storms between the 2015/16 and 2016/17 summer seasons.

The diurnal rate of decay in lightning incidence requires further observations, but current results indicate a low probability of lightning occurring in the earlymorning hours at Kinsevere. However, note that lightning occurrences at Kinsevere were not limited to the late-afternoon hours, which emphasizes the need for an automated system that operates $24 \mathrm{~h}$ per day.

During escalation of the alarms, most of the escalations were from a state 1 to 2 . However, the majority escalated further to alarm state 3 (Fig. 2 in the online supplementary material). In addition, most events $(72.6 \%$ and $78.0 \%$ in the two years of data) ended at warning state 3 , and more time was spent in alarm state 3 than in alarm state 2 throughout the dataset (Fig. 1 in the online supplementary material). It is evident that if there is a state- 2 warning then a state- 3 warning is likely to follow. For clarity and simplicity of the lightning warning policy, it would be beneficial to consider a simplified warning system with only two states; state 1 (all clear) and state 2 (alarm). This may be particularly beneficial where lightning response policy indicates minimal difference in the actions to be taken by employees for a "caution" state and a "red" state. However, the thresholds (electric field and distance to flashes) for this single warning would have to be considered.

The analysis of warning-state elevations emphasized the importance of monitoring both the electrical field and flashes because either or both probably provided elevations, depending on storm characteristics and development. Warnings for storms developing over Kinsevere may have been provided through electricalfield triggers, whereas fully developed storms moving over or past Kinsevere may have been provided initially by the SG000. More complex is to identify the level at which detectable triggers should be considered warnings. We conclude that there appears to be a lack of information with regard to critical thresholds at which to trigger lightning warnings. This may be because these triggers are site dependent and/or may be due to a reticence to publish recommendations because of uncertainty around lightning as well as possible legal implications.

Through the application of the system at Kinsevere over a 2-yr period, a few practical recommendations are possible. Battery capacity and current drain of the system components should be well understood in remote areas where "mains electricity" may be unreliable. At Kinsevere, $18 \mathrm{~A} \mathrm{~h}$ battery packs were found to be sufficient for the CS110 and 24 A h battery packs were sufficient for the RA110 because of the current drain of the beacons (and sirens in some cases). In addition, a computer that stores data should be run off an adequate, uninterruptable power supply. Communication interruption of the warning requires careful consideration. At Kinsevere, there has been considerable benefit in providing warning through both the LAN and Vijeo Citect SCADA network system and additionally operating the CS110 and main RA110, which triggers the 380-VAC siren, on a stand-alone radio system. In this way, any computer issues or LAN problems do not affect the main RA110 and the siren continues to function. Should any problems with the SCADA network occur, the computer continues downloading data, sending e-mail messages, and disseminating the warning state to the LAN-networked RA110 systems. To maximize redundancy of the warning system, regular inspection with cleaning and servicing of the CS110 station, in particular, is required. Dust, spider webs, and bird nests were the main problems addressed. Last, because of the safety-critical nature of the equipment, it is recommended that spares be kept on site (especially at remote sites). A complete backup system can be stored on site and set up should there be equipment failure, or a backup CS110 can be operated permanently. If the primary CS110 system should fail, the backup system automatically takes over in determining the flashes and electric-field measurements.

\section{Conclusions}

Lightning is known to damage infrastructure, ignite severe wildfires, and result in extreme human injury and fatality (Mulder et al. 2012; Nauslar 2014). While much research has focused on the spatiotemporal characteristics of lightning activity across the world, very little has been done to assess operational ground-based early warning systems. On some continents, such as North America and Europe, wide-area and long-range systems are available for lightning detection and warning, but in the DRC there is no alternative other than to use a ground-based LWS. From global lightning distribution maps captured by satellites, the Kinsevere area has less lightning than the areas in northern DRC but enough to be of significant concern. Ground-measured annual flash densities compared relatively poorly to satellite results, but this result was consistent with existing studies, and the complexities in comparing ground-based measurements with satellite detection were noted.

The research investigated the temporal characteristics of lightning and the atmospheric electrical field in the southern Congo basin and assessed the operational 
use of a ground-based lightning warning system. The Kinsevere copper mine in the southern DRC has been utilizing such a system since early 2015. A dual-sensor approach, with warning dissemination through two separate communication networks, was found to be useful. Sufficient battery capacity, equipment service intervals, and backup systems were important. The main obstacles experienced included some false alarms in winter, uncertainty in site-specific trigger requirements (particularly in terms of the electric field), and lightning damage to a network adaptor of the LWS equipment itself. However, the system has been shown to produce reasonable lightning early warnings.

This research illustrates the value of ground-based early warning systems for private corporations and nongovernment entities that are not within an area covered by continent-wide lightning-locating systems. Future research to consider the relationship between microclimate measured at Kinsevere and lightning activity in the region surrounding the mine would be beneficial and could be used to reduce false alarms.

Acknowledgments. MMG funded the research. Numerous staff at MMG, including Alan Tatton, Ockert Foerie, Hugues Manung, Gloria Mbaz, Grant Southey, and Erik Botha were pivotal in developing the lightning warning system and are thanked for their support.

\section{REFERENCES}

Albrecht, R. I., S. J. Goodman, D. E. Buechler, R. J. Blakeslee, and H. J. Christian, 2016: Where are the lightning hotspots on Earth? Bull. Amer. Meteor. Soc., 97, 2051-2068, https:// doi.org/10.1175/BAMS-D-14-00193.1.

Avila, E. E., and R. G. Pereyra, 2000: Charge transfer during crystal-graupel collisions for two different cloud droplet size distributions. Geophys. Res. Lett., 27, 3837-3840, https:// doi.org/10.1029/2000GL012302.

Basher, R., 2006: Global early warning systems for natural hazards: Systematic and people-centred. Philos. Trans. Roy. Soc., 364A, 2167-2182, https://doi.org/10.1098/rsta.2006.1819.

Bennett, A. J., and R. G. Harrison, 2007: Atmospheric electricity in different weather conditions. Weather, 62, 277-283, https:// doi.org/10.1002/wea.97.

Blumenthal, R., E. Trengrove, I. R. Jandrell, and G. Saayman, 2012: Lightning medicine in South Africa. S. Afr. Med. J., 102, 625-626, https://doi.org/10.7196/SAMJ.5219.

Boccippio, D. J., W. J. Koshak, and R. J. Blakeslee, 2002: Performance assessment of the Optical Transient Detector and Lightning Imaging Sensor. Part I: Predicted diurnal variability. J. Atmos. Oceanic Technol., 19, 1318-1332, https://doi.org/ 10.1175/1520-0426(2002)019<1318:PAOTOT>2.0.CO;2.

Booth, G., A. Cameron, G. Fahey, and M. Lawlor, 2010: Kinsevere copper project. Anvil Mining Limited Tech. Rep. NI 43-101, 288 pp.

Christian, H. J., and Coauthors, 2003: Global frequency and distribution of lightning as observed from space by the Optical
Transient Detector. J. Geophys. Res., 108, 4005, https:// doi.org/10.1029/2002JD002347.

Collier, A. B., and A. R. W. Hughes, 2011: A harmonic model for the temporal variation of lightning activity over Africa. J. Geophys. Res., 116, D05105, https://doi.org/10.1029/2010JD014455.

Cummins, K. L., and M. J. Murphy, 2009: An overview of lightning locating systems: History, techniques, and data uses, with an indepth look at the U.S. NLDN. IEEE Trans. Electromagn. Compat., 51, 499-518, https://doi.org/10.1109/TEMC.2009.2023450.

Dwyer, J. R., and M. A. Uman, 2014: The physics of lightning. Phys. Rep., 534, 147-241, https://doi.org/10.1016/ j.physrep.2013.09.004.

Hembury, N., and R. Holle, 2011: Flash of inspiration: Latest innovations in worldwide lightning detection. Meteorological Technology International, May 2011, UKIP Media, Dorking, United Kingdom, 48-50.

Jackson, B., S. E. Nicholson, and D. Klotter, 2009: Mesoscale convective systems over western equatorial Africa and their relationship to large-scale circulation. Mon. Wea. Rev., 137, 1272-1294, https://doi.org/10.1175/2008MWR2525.1.

Jandrell, I. R., R. Blumenthal, R. B. Anderson, and E. Trengove, 2009: Recent lightning research in South Africa with a special focus on keraunopathology. Proc. 16th Int. Symp. High Voltage Engineering, Cape Town, South Africa, South African Institute of Electrical Engineers, $15 \mathrm{pp}$.

Jury, M. R., and E. J. Mpeta, 2009: African climate variability in the satellite era. Theor. Appl. Climatol., 98, 279-291, https:// doi.org/10.1007/s00704-009-0106-0.

Kadima, E., D. Delvaux, S. N. Sebagenzi, L. Tack, and S. M. Kabeya, 2011: Structure and geological history of the Congo basin: An integrated interpretation of gravity, magnetic and reflection seismic data. Basin Res., 23, 499-527, https://doi.org/ 10.1111/j.1365-2117.2011.00500.x.

Mulder, M. B., L. Msalu, T. Caro, and J. Salerno, 2012: Remarkable rates of lightning strike mortality in Malawi. PLOS ONE, 7, e29281, https://doi.org/10.1371/journal.pone.0029281.

Nag, A., M. J. Murphy, W. Schulz, and K. L. Cummins, 2015: Lightning locating systems: Insights on characteristics and validation techniques. Earth Space Sci., 2, 65-93, https:// doi.org/10.1002/2014EA000051.

Nauslar, N. J., 2014: Examining the lightning polarity of lightning caused wildfires. 23rd Int. Lightning Detection Conf., Tucson, AZ, Vaisala, 15 pp., https://my.vaisala.net/Vaisala\% 20Documents/Scientific\%20papers/2014\%20ILDC\%20ILMC/ ILDC-Wednesday/Nauslar-Examining\%20the \%20Lightning \% 20Polarity\%20of\%20Lightning \%20Caused\%20Wildfires-2014ILDC-ILMC.pdf.

Roy, S. S., and R. C. Balling Jr., 2014: Spatial patterns of diurnal lightning activity in southern Africa during austral summer. Atmos. Res., 145-146, 182-188, https://doi.org/10.1016/ j.atmosres.2014.03.026.

Stolzenburg, M., W. D. Rust, and T. C. Marshall, 1998: Electrical structure in thunderstorm convective regions: 3. Synthesis. J. Geophys. Res., 103, 14 097-14 108, https://doi.org/10.1029/ 97JD03545.

Taszarek, M., B. Czernecki, and A. Koziol, 2015: A cloud-toground lightning climatology for Poland. Mon. Wea. Rev., 143, 4285-4304, https://doi.org/10.1175/MWR-D-15-0206.1.

Thompson, K., M. Bateman, and L. Carey, 2014: A comparison of two ground-based lightning detection networks against the satellite-based Lightning Imaging Sensor (LIS). J. Atmos. Oceanic Technol., 31, 2191-2205, https:// doi.org/10.1175/JTECH-D-13-00186.1. 
Washington, R., R. James, H. Pearce, W. M. Pokam, and W. Moufouman-Okia, 2013: Congo basin rainfall climatology: Can we believe the climate models? Philos. Trans. Roy. Soc., 368B, 20120296, https://doi.org/10.1098/rstb.2012.0296.

Williams, E. R., and Coauthors, 2010: Ground-based detection of sprites and their parent lightning flashes over Africa during the 2006 AMMA campaign. Quart. J. Roy. Meteor. Soc., 136, 257-271, https://doi.org/10.1002/qj.489.

Xia, R., D. L. Zhang, and B. Wang, 2015: A 6-yr cloud-to-ground lightning climatology and its relationship to rainfall over central and eastern China. J. Appl. Meteor. Climatol., 54, 2443-2460, https://doi.org/10.1175/JAMC-D-15-0029.1.

Zajac, B. A., and S. A. Rutledge, 2001: Cloud-to-ground lightning activity in the contiguous United States from 1995 to 1999. Mon. Wea. Rev., 129, 999-1019, https://doi.org/10.1175/15200493(2001)129<0999:CTGLAI>2.0.CO;2.

Zipser, E. J., D. J. Cecil, C. Liu, S. W. Nesbitt, and D. P. Yorty, 2006: Where are the most intense thunderstorms on Earth? Bull. Amer. Meteor. Soc., 87, 1057-1071, https://doi.org/ 10.1175/BAMS-87-8-1057. 